\title{
Role of superdisintegrants in immediate release tablets: A review
}

\author{
Shashikant N. Sharma ${ }^{1}$, Ravindra S. Sonawane ${ }^{2}$ \\ ${ }^{1}$ Department of Pharmacology, Smt. Sharadchandrika Suresh Patil Institute of Technology, Chopda, Maharashtra, India, ${ }^{2}$ Department of Pharmacognosy, Smt. Sharadchandrika \\ Suresh Patil Institute of Technology, Chopda, Maharashtra, India
}

Correspondence:

Shashikant N. Sharma, Department of

Pharmacology, Smt. Sharadchandrika Suresh

Patil Institute of Technology, Chopda,

Maharashtra, India. Mob. No. 09860397993

E-mail: Bharath jain2006@gmail.com

\begin{abstract}
Immediate release oral dosage forms, i.e., tablets and capsules, are most widely used drug delivery systems available because of its convenience of self-administration, compactness, and easy manufacturing. These products are designed to disintegrate in the stomach followed by their dissolution in the fluids of the gastrointestinal tract. Immediate drug release dosage forms disintegrate rapidly after administration with enhanced rate of dissolution. Superdisintegrants are used to improve the efficacy of solid dosage forms. This is achieved by decreasing the disintegration time which in turn enhances the drug dissolution rate. Superdisintegrants are generally used at a low level in the solid dosage form, typically $1-10 \%$ by weight relative to the total weight of the dosage unit. The basic approach used in development tablets is the use of superdisintegrants such as cross-linked polyvinylpyrrolidone or crospovidone (polyplasdone), sodium starch glycolate (primogel, explotab), and carboxymethylcellulose (croscarmellose). These superdisintegrants provide instantaneous disintegration of tablet after administration in the stomach. The present review comprises the various kinds of superdisintegrants such as natural and synthetic which are being used in the formulation to provide the safer, effective drug delivery with patient's compliance. The various sources of superdisintegrants and their modification to improve disintegration property are also highlighted.
\end{abstract}

Keywords: Immediate release oral dosage forms, superdisintegrant, gastrointestinal, disintegration property

\section{Introduction}

Many patients especially children and elderly have difficulty in swallowing tablets and capsules and consequently unable to take medicine as prescribed. Almost $40-50 \%$ of the population is affected by such problem, resulting in the high incidence of noncompliance and ineffective therapy. Despite increasing interest in controlled release drug delivery systems, the most common tablets are those intended to be swallowed whole and to disintegrate and release

\section{Access this article online}

Website: http://www.jpbs-online.com

E-ISSN: 2321-0125

DOI: $10.31555 / j p b s / 2017 / 5 / 1 / 1-5$

How to cite this article: Sharma SN, Sonawane RS. Role of superdisintegrants in immediate release tablets: A review. J Pharm BioSci 2017;5(1):1-5.

Source of Support: Nil, Conflict of Interest: None declared. their medicaments rapidly in the gastrointestinal tract still remains the dosage form of choice. As disintegration plays a crucial role, so for the development of solid orals, formulators are fascinating toward selection of proper disintegrants/superdisintegrants in dosage systems.

Tablet disintegration has received considerable attention as an essential step in obtaining fast drug release. The emphasis on the availability of drug highlights the importance of the relatively rapid disintegration of a tablet as a criterion for ensuring uninhibited drug dissolution behavior.

Superdisintegrants are the agents added to tablet and some encapsulated formulations to promote the breakup of the tablet and capsule "slugs" into smaller fragments in an aqueous environment thereby increasing the available surface area and promoting a more rapid release of the drug substance. They promote moisture penetration and dispersion of the tablet matrix (Table 2). ${ }^{[1-3]}$

The disintegration of dosage forms are depends on various physical factors of superdisintegrants. ${ }^{[4,5]}$ 
They are as follow:

1. Percentage of disintegrants present in the formulation

2. Proportion of disintegrants used

3. Compatibility with other excipients

4. Presence of surfactants

5. Hardness of the tablets

6. Nature of Drug substances

7. Mixing and types of addition.

A disintegrate used in granulated formulation processes can be more effective if used both "intragranularly" and "extragranularly" thereby acting to break the tablet up into granules and having the granules further disintegrate to release the drug substance into solution. However, the portion of disintegrate added intragranularly (in wet granulation processes) is usually not as effective as that added extragranularly because it is exposed to wetting and drying (as part of the granulation process) which reduces the activity of the disintegrate. Since a compaction process does not involve its exposure to wetting and drying, the disintegrate used intragranularly tends to retain good disintegration activity.

Moreover, hence, the proper choice of a disintegrant or a superdisintegrants and its consist performance are of critical importance to the formulation development of such immediate release tablets. ${ }^{[6]}$

They all should possess the following characteristics:

1. Poor water solubility with good hydration capacity

2. Poor gel formation

3. Good flow properties

4. Good compressibility

5. Inert

6. Non-toxic

7. Requirement of least quantity.

\section{Method of Incorporation}

The incorporation of superdisintegrants in the dosage forms are mainly of three types.

\section{Intragranular or during granulation}

In this process, the superdisintegrants are blend with other powders and granulation is carried out. Thus, the superdisintegrants are incorporated within the granules.

\section{Extragranular or before compression}

In this process, the superdisintegrants are mixed with prepared granules before compression.

\section{Incorporation of superdisintegrants at intra- and extra-granulation steps}

In this process, part of superdisintegrants are added to intragranular and a part to extragranules. This method usually produces better results and more complete disintegration than Type I and Type II. ${ }^{[7]}$

\section{Mechanism of Disintegrations by \\ Superdisintegrants ${ }^{[8,9]}$}

\section{Swelling}

Although not all effective disintegrants swell in contact with water, swelling is believed to be a mechanism in which certain disintegrating agents (such as starch) impart the disintegrating effect. By swelling in contact with water, the adhesiveness of other ingredients in a tablet is overcome causing the tablet to fall apart.

\section{Porosity and capillary action (wicking)}

Effective disintegrants that do not swell are believed to impart their disintegrating action through porosity and capillary action. Tablet porosity provides pathways for the penetration of fluid into tablets. The disintegrant particles (with low cohesiveness and compressibility) themselves act to enhance porosity and provide these pathways into the tablet. Liquid is drawn up or "wicked" into these pathways through capillary action and rupture the interparticulate bonds causing the tablet to break apart (Figure 1).

\section{Deformation}

Starch grains are generally thought to be "elastic" in nature meaning that grains that are deformed under pressure will return to their original shape when that pressure is removed. However, with the compression forces involved in tableting, these grains are believed to be deformed more permanently and are said to be "energy rich" with this energy being released upon exposure to water. In other words, the ability for starch to swell is higher in "energy rich" starch grains than it is for starch grains that have not been deformed under pressure. It is believed that no single mechanism is responsible for the action of most disintegrants. But rather, it is more likely the result of inter-relationships between these major mechanisms.

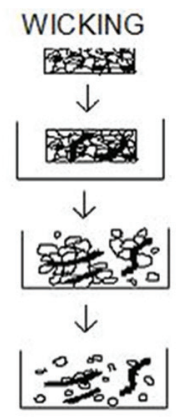

Water is pulled into pores by disintegrant and reduce the physical bonding forces between particles

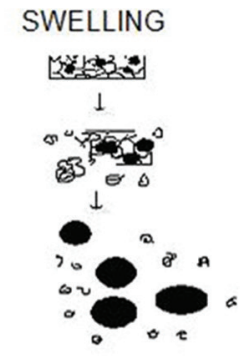

Particles swell and break up the matrix from within; swelling sets up; localized stress spreads throughout the matrix
Figure 1: Disintegration of tablet by wicking and swelling 


\section{Due to disintegrating particle/particle repulsive forces}

Another mechanism of disintegration attempts to explain the swelling of tablet made with "nonswellable" disintegrants. Guyot-Hermann has proposed a particle repulsion theory based on the observation that nonswelling particle also causes disintegration of tablets. The electric repulsive forces between particles are the mechanism of disintegration and water is required for it. Researchers found that repulsion is secondary to wicking (Figure 2).

\section{Super-disintegrants Used in Dosage Forms ${ }^{[10-14]}$}

\section{Sodium starch glycolate (SSG) $\left(\right.$ Explotab $^{\circledR}$ and Primoge $\left.{ }^{\circledR}\right)$}

The oldest and probably the most widely used disintegrant, the starch is modified with a dramatic disintegrating properties and are available as Explotab ${ }^{\circledR}$ and Primogel ${ }^{\circledR}$. These are low substituted carboxymethyl starches in granular forms. The mechanism involves rapid absorption of water leading to an enormous increase in the volume of granules result fast and uniform disintegration. When these superdisintegrants are used in formulations, they show the disintegration of solid dosage form within $2 \mathrm{~min}$. The higher dissolution rates observed with superdisintegrants may be due to rapid disintegration and fine dispersion of particles formed after disintegration (Figure 3).

$\begin{array}{ll}\text { Particles swell to precompression } \\ \text { size and break up the matrix } & \text { Water is drawn into the pores and } \\ & \text { particles repel each other because } \\ \text { of the resultina electrical force }\end{array}$

Figure 2: Disintegration by deformation and repulsion

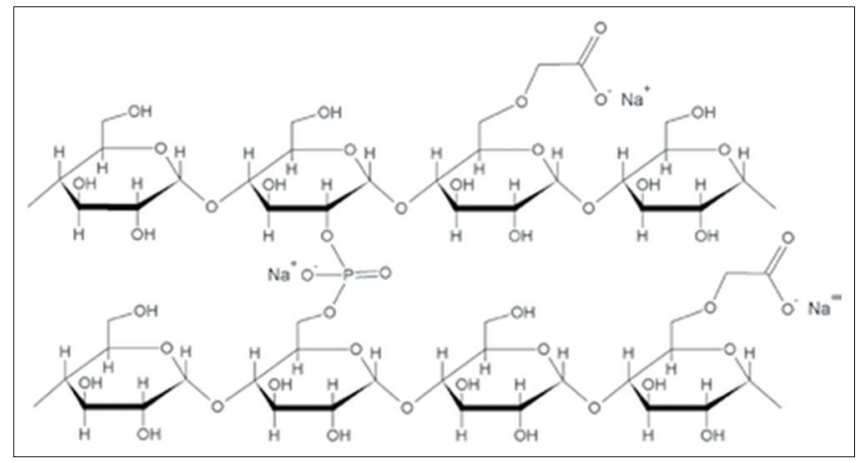

Figure 3: Basic structure of sodium starch glycolate

\section{Cross-linked polyvinylpyrrolidone (cross povidone)}

In case of mouth-dissolving formulations, crospovidone quickly wicks saliva into them to generate the volume expansion and hydrostatic pressures necessary to provide rapid disintegration in the mouth. Unlike other superdisintegrants, it relies on both swelling and wicking principally for disintegration. When examined under a scanning electron microscope, crospovidone particles appear to be granular and highly porous. This unique, porous nature facilitates wicking of liquid into the dosage systems and causes rapid disintegration. Due to high crosslink density of crospovidone, it swells rapidly in water without gel formation than others (Table 1).

In contrast to other superdisintegrants such as SSG and croscarmellose sodium, crospovidone exhibit virtually no tendency toward gel formation, even at a high ratio. As disintegrants that result gel formation is not appreciable in orally disintegrating tablets (ODT) and chewable products (Figure 4).

\section{Cellulose derivatives $\left(\right.$ Ac-Di-Sol ${ }^{\circledR}$ )}

Croscarmellose sodium is described as a cross-linked polymer of carboxymethylcellulose. This polymer is different in synthesis and structure as compared to SSG. Most importantly, the degree of substitution using Williamson's ether synthesis of croscarmellose sodium is higher than that of SSG, and the mechanism of crosslinking is also different. The chemistry of SSG is different that of croscarmellose sodium. As some of the carboxymethyl groups themselves are used to cross-link the cellulose chains. For example, the cross-linking in Primogel is phosphate ester rather than carboxyl ester links as compared to croscarmellose sodium (Figure 5).

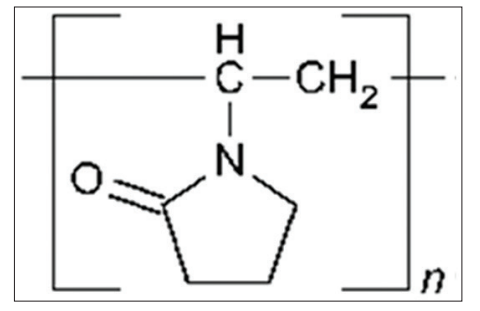

Figure 4: Basic structure of crospovidone

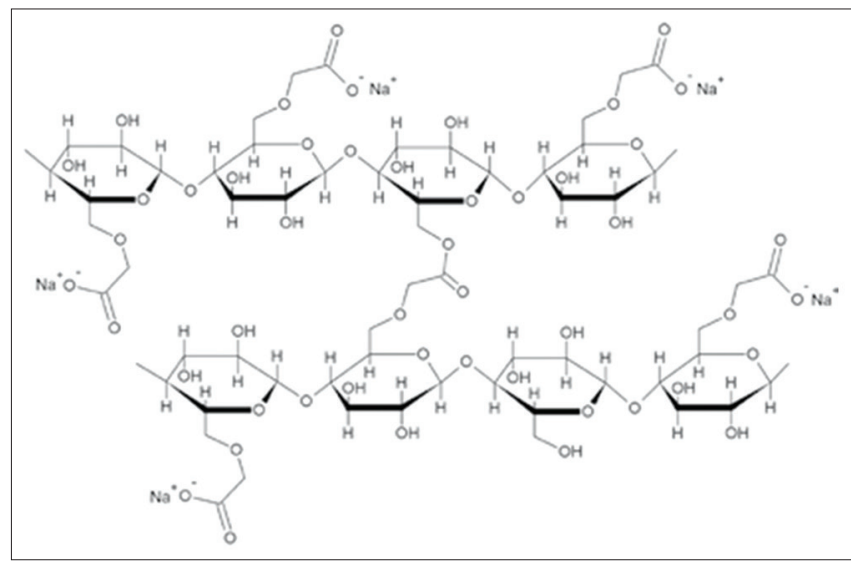

Figure 5: Basic structure of croscarmellose sodium 


\begin{tabular}{|c|c|c|c|}
\hline Superdisintegrants & Commercially available grades & Mechanism of action & Special comment \\
\hline Cross-linked cellulose & $\begin{array}{l}\text { Crosscarmellose }^{\circledR} \text { Ac-Di-Sol }{ }^{\circledR}, \text { Nymce ZSX }^{\circledR} \\
\text { Primellose }^{\circledR}, \text { Solutab }^{\circledR}, \text { Vivasol }^{\circledR} \text {, L-HPC }\end{array}$ & $\begin{array}{l}\text { Swells 4-8 folds in }<10 \mathrm{~s} \\
\text { Swelling and wicking both }\end{array}$ & $\begin{array}{l}\text { Swells in two dimensions } \\
\text { Direct compression or granulation } \\
\text { Starch free }\end{array}$ \\
\hline Cross-linked PVP & $\begin{array}{l}\text { Crospovidone } \mathrm{M}^{\circledR} \\
\text { Kollidon }^{\circledR} \\
\text { Polyplasdone }^{\circledR}\end{array}$ & $\begin{array}{l}\text { Swells very little and returns to original size } \\
\text { after compression but act by capillary action }\end{array}$ & $\begin{array}{l}\text { Water insoluble and spongy in nature } \\
\text { so get porous tablet }\end{array}$ \\
\hline Cross-linked starch & $\begin{array}{l}\text { Explotab }^{\circledR} \\
\text { Primogel }^{\circledR}\end{array}$ & Swells $7-12$ folds in $<30 \mathrm{~s}$ & $\begin{array}{l}\text { Swells in three dimensions and high } \\
\text { level serve as sustain release matrix }\end{array}$ \\
\hline Cross-linked alginic acid & Alginic acid NF & $\begin{array}{l}\text { Rapid swelling in aqueous medium or } \\
\text { wicking action }\end{array}$ & $\begin{array}{l}\text { Promote disintegration in both dry } \\
\text { or wet granulation }\end{array}$ \\
\hline Soy polysaccharides & Emcosoy ${ }^{\circledR}$ & & $\begin{array}{l}\text { Does not contain any starch or } \\
\text { Sugar. Used in nutritional products }\end{array}$ \\
\hline Calcium silicate & & Wicking action & Highly porous, light weight \\
\hline
\end{tabular}

Table 2: Superdisintegrants used in immediate release formulations

\begin{tabular}{lllll} 
Drug & Superdisintegrants & Method & Formulation & References \\
\hline Gliclazide & Crospovidone Ac-Di-Sol & Direct compression & Fast dissolving tablet \\
& SSG & & \\
Disulfiram & SSG (glycolis Type A) & Dry granulation, slugging & Immediate release tablet \\
Ibuprofen & Kollidon CL (K) & Wet granulation & Fast dissolving tablets \\
Losplotab (E) & & Taste masked fast dissolving tablets \\
Granisetron $\mathrm{HCl}$ & Crospovidone Ac-Di-Sol & Direct compression & \\
\hline
\end{tabular}

\section{Microcrystalline cellulose (avicel)}

Avicel concentration of $<10 \%$, exhibits better disintegration. This mechanism is depending on the entry of water to the tablet matrix through capillary pores, which breaks the hydrogen bonding between adjacent bundles of cellulose microcrystals. With more concentration, particularly in oral disintegrating tablet, it shows a tendency to stick to the tongue due to rapid capillary absorption and faster dehydration of the tablet surface. As Avicel has a fast wicking rate for water, hence this in combination with starch makes an excellent and rapid disintegration in OTD formulations.

\section{Ion exchange resins}

The INDION 414 has been used as a superdisintegrant for ODT. It is chemically cross-linked polyacrylic, with a functional group of $\mathrm{COO}-$ and the standard ionic form is $\mathrm{K}+$. It has a high water uptake capacity. It is a high purity pharmaceutical grade weak acid cation exchange resin supplied as a dry powder. It is an extremely effective tablet disintegrant which provides the necessary hardness and chemical stability to the tablet. The product swells up to a very great extent when in contact with water or gastrointestinal fluids causing rapid disintegration without the formation of lumps. It is a high molecular weight polymer; therefore, it is not absorbed by the human tissues and totally safe for human consumption.

\section{Natural superdisintegrants}

Agar (AG) and guar gum (GG), natural polysaccharides are treated with water and co-grinded further with mannitol which exhibits superdisintegration property. These modified polysaccharides may call co-grinded treated agar (C-TAG) and co-grinded-treated GG (C-TGG), respectively. They are biodegradable, directly compressible, having desirable swelling dynamics. The C-TAG and C-TGG have shown better disintegration for their porous nature, better water intake ability, and free flowing property than others.

Another natural polysaccharide, karaya gum is modified using distilled water to achieve superdisintegration property in dispersible tablet development. This modified karaya gum is easy to prepare, cheap, easily available, biodegradable, and stable compared to available synthetic super disintegrants in market.

Mucilage of plantago ovata seed husk (isapghula) is also used as superdisintegrants. The mucilage of plantago ovata is a recent innovation for its super disintegration property when compared with crospovidone. It shows faster disintegration time than the superdisintegrants, crospovidone.

\section{Conclusion}

Overviews of various superdisintegrants which are available have been discussed. The ease of availability of these agents and the simplicity in the direct compression process suggest that their use would be a more economic alternative in the preparation of immediate release tablets than the sophisticated techniques. The uses of superdisintegrants are extended in the applications of oral disintegration tablets, fast-dispersible tablets, capsules, and mouthdissolving films. 


\section{References}

1. Sood R, Rathore MS, Sharma A, Thakur R, Chaudhari J, Soni V. Immediate release antihypertensive valsartan oral tablet: A review. J Sci Res Pharm 2012;1:20-6.

2. Swarbrick J. Encyclopedia of Pharmaceutical Technology. $3^{\text {rd }}$ ed. New York: Informa Healthcare USA, Inc.; 2000. p. 3641, 3657-9, 3612-3, 3928.

3. Ansel HC, Popvich NG, Allen LV. Pharmaceutical Dosage Forms and Drug Delivery System. $1^{\text {st }}$ ed. New York: Marcel Dekker Inc.; 1998. p. 78.

4. Schimidt PC, Brogramann B. The role of disintegrants in solid oral dosage manufacturing. Pharm Technol 1988;34:22.

5. Cohen Y, Lach JL. Cycloheptaamylose inclusion complexes of barbiturates. J Pharm Sci 1963;52:122.

6. Shihora H, Panda S. Superdisintegrants, utility in dosage forms: A quick review. J Pham Sci Bio Sci Res 2011;1:148-53.

7. Bhaskaran $\mathrm{S}$, Narmada GV. Rapid dissolving tablet a novel dosage form. Indian Pharm 2002;1:912.

8. Kuchekar BS, Bhise SB, Arungam V. Design of fast dissolving tablets. Indian J Pharm Educ 2005;35:150.

9. Reddy LH, Ghosh B, Shree B, Rajneesh. Fast dissolving drug delivery system: A review of literature. Indian J Pharm Sci 2002;64:331-6.

10. List PH, Muazzamm UA. Swelling - A driving force in tablet disintegration. Pharm Ind 1979;41:1075-7.

11. Caramella C. Novel methods for disintegrant characterization, Part 1. Pharm Technol Int 1990;2:30-7.
12. Shangraw R, Wallace J, Bowers F. Morphology and functionality in tablet excipients for direct compression. Pharm Technol 1981;5:44-60.

13. Shangraw R, Mitrevej A, Shah M. A new era of tablet disintegrants. Pharm Technol 1980;4:48-57.

14. European Directorate for the Quality of Medicines. European Pharmacopeia. Vol. 5. Strasbourg: European Directorate for the Quality of Medicines; 2006. p. 3151 .

15. Cremer K. Orally disintegrating dosage forms provide life cycle management opportunities. Pharm Technol Formul Solid Dosage 2003;2009:22-8.

16. Parakh SR, Gothosakar AV. A review of mouth dissolving tablet technologies. Pharm Technol 2003;27:92-100.

17. Duriez X, Joshi AA. Starches a versatile source. Pharm Form Qual 2004;6:48-50.

18. Chandra MS, Shinde SP, Parthiban KG, Krishnarajan D, Manivannan R. Extending the drug release of fast dissolving tablets of gliclazide. Imp J Pharm Cosmetol 2011;1:30-7.

19. Pathak N, Kumar A, Methkar V, Pant P, Rao RT. Formulation and optimization of immediate release tablet of an antialcohlic drug by dry granulation method. Int J Compr Pharm 2011;3:1-4.

20. Fini A, Bergamante V, Ceschel GC, Ronchi C, de Moraes CA. Fast dispersible/ slow releasing ibuprofen tablets. Eur J Pharm Biopharm 2008;69:335-41.

21. Avulapati S, Roy AK, Shashidhar KR, ReddyTU. Formulation and evaluation of taste masked and fast disintegrating losartan potassium tablets. Int J Drug Dev Res 2011;3:45-51.

22. Patil BS, Rao KD, Kulkarni U, Gada MM, Soodam SR. Formulation and evaluation of fast dissolving tablets of granisetron hydrochloride. Int J Appl Biol Pharm Technol 2011;2:22-8. 